\title{
Chapter 3 \\ Perception, Amplification \\ and Communication: A Case Study \\ of Food Safety Risks
}

\subsection{Research Background and Significance}

\subsubsection{Research Background}

In recent years, China has seen a rapid increase in public health incidents, among which food safety incidents have drawn the most attention. Every major food safety incident is a challenge to the safety warning line and leads to various social consequences in addition to economic losses. Food is the first necessity of the people, and food safety is of paramount importance. Any incident concerning food safety will spark public concern, and if not properly handled, may cause social panic.

According to the results of 2006 and 2008 surveys by the Chinese Academy of Social Sciences (CASS), the sense of security about food was at the lowest level compared with that about other factors.

This shows that the public have long been concerned about food hygiene and safety, as evidenced in food safety incidents exposed since September 2008 such as the use of melamine in milk and chicken feed. Just as the negative effects of the "Fuyang inferior milk powder incident" were lingering, the 2008 milk scandal again exacerbated the public's health concerns. In face of risks, what the people care about the most is not how to precisely measure risks, but whether their own survival and safety is threatened. Therefore, as to the public's question of "to what extent can safety be guaranteed", risk managers and decision-makers should address the issue from a cultural perspective, and explore the internal logic of risk behavior, so as to shed light on the social and cultural process that shapes risks and draw conclusions that are useful for food safety management. 


\subsubsection{Research Significance}

On a theoretical level, this research focuses on the serious consequences except casualties and property losses in food safety incidents, and regards these consequences as social consequences, which are deeper-level impacts of the incidents. This is a way to correct the shortcomings of "cost effectiveness" analysis, which underestimates the negative effects of incidents. To study the social dynamics of risk perception and amplification is to provide such a correction mechanism for risk analysis and decision-making. On the one hand, it is necessary to prevent the exaggeration of a particular risk from heightening individual or social risk perception and causing overreaction from the public. On the other hand, it is also important to prevent people from underestimating and "understating" the risk and thus responding inadequately when a risk is intentionally or unintentionally neglected. The social consequences of risks and incidents should neither be underestimated nor deliberately exaggerated; instead, risks should be assessed in an accurate and holistic manner. In this way, the concept of social amplification or attenuation of risk can be separated from individual experience and social intention, which will help to understand risks more comprehensively.

From a practical perspective, China has seen a number of major food safety incidents in recent years, which pose a huge threat to public health, property safety and social order. These incidents generally raise great concerns and cause serious social consequences that often go beyond the existing capabilities of the government and society. Therefore, in-depth case studies are required. By reconstructing typical cases in specific social and historical contexts, and analyzing their occurrence mechanism and the influence of cultural and social process on them, these studies can shed light on how the relationship between mainstream culture and group subculture affects the process of social amplification or attenuation of risk, and demonstrate the social process of dealing with risks, such as the interaction between the riskrelated experiences of individuals and society. Only by strengthening case studies on food safety incidents and exploring the path of social amplification of risk can we better understand the meaning of shaping a society's risk-related experience, enhance people's sense of risk, transform the governance structure of emergencies, and improve emergency management of the government. The purpose of this study is to explain, using the framework of social amplification of risk, the mechanisms and modes of interaction between different incidents and psychological, social and cultural factors in contemporary China, so as to provide theoretical explanations that suit China's risk governance experience. 


\subsection{Analytical Framework and Research Methods}

\subsubsection{Core Concepts}

\subsubsection{1 "Risk" and "Perceived Risk"}

"Risk" is closely related to "hazard". "Risk" generally refers to the substances and incidents that pose threats to human beings and their habitat and manmade facilities, as well as some scenarios that threaten the survival and development of mankind. In most contexts, risk is construed as an undesired incident. Technically, risk can be quantified as the product of the probability of the undesired incident and the scale of particular consequences.

In contrast, cultural studies think that risk, in nature, is constructed, and risk perception is people's judgement and assessment of the hazards that are affecting or may affect them, including their health, life, property and living environment. The effects of such judgement and assessment may be amplified or attenuated in social settings, and bring about other social consequences. Most people has a more comprehensive understanding of risk than the aforesaid "product", and some aspects of risk, such as voluntariness, weighing of interests, and destructiveness and potentiality of risk, all have influence on people's perception of and response to risks. This indicates that no matter how risk is defined scientifically, only risks that are generally perceived by people in particular social contexts are "real".

In fact, risk research is a scientific activity and also a kind of cultural explanation. The complexity of world determines that risk research and risk assessment and management are becoming more and more complicated. Technical measurements and the approaches of cultural studies should be combined. This can extend the concept of risk, and help to better understand how people experience, assess and respond in face of risks. Therefore, risk can be regarded as the probability of the consequences that people's action, a scenario or an incident may result in. Risk, on one part, is partly an objective threat to people, and on the other part, is a product of culture and social experiences. This implies the causality between different incidents (actions), and that losses and damages are always substantial; meanwhile, the risk-related experiences brought by such losses and damages to the public are "embedded" into cultural, social and psychological fabrics.

\subsubsection{2 "Risk Amplification"}

"Amplification" originates from the analogy of electronic signals. The effects of risk amplification can be divided into direct effects (physical amplification) and indirect ripple effects (social amplification). The former will bring about health injury, property loss and other adverse consequences, and the latter, a result of interactions between the direct consequences and social handing process of risks, will lead to changes in medical costs and social emergency response costs, stigmatization of 
social organizations, group conflicts, cover-up and whitewash of social contradictions, decline in collective morality, and so on. Specifically, natural disasters mainly give rise to the direct amplification of physical energy, while public health incidents and social security incidents mainly result in indirect ripple effects.

A concept related to social amplification is social attenuation. Due to social amplification of risk, the effects caused by emergencies will lead to additional institutional responses and protective actions, while in the case of social attenuation of risk, individuals and society will underestimate and underreact to risks and thus reduce protective actions. When physical amplification and social amplification are considered together, risk amplification or attenuation is regarded as the expansion or reduction of the ripple effects of particular incidents. Amplification or attenuation turns the direct effects of incidents into the ripple effects. In this process, the impact of risk goes beyond when and where an incident occurs and gets into a broader social field.

\subsubsection{3 "Risk Amplifier"}

The intermediary that disseminates the energy and information of the initial incident into the society is called "amplifier". In the process of risk amplification, riskrelated information is aggregated and reinterpreted through the social process in which people or groups communicate information with others. The individuals or organizations that gather and respond to risk-related information are called "social amplifiers" of risk. They mainly include news media, government, experts, enterprises, personal networks, and individual actors (including direct stakeholders and non-direct stakeholders). Risk amplifiers can be divided into "physical amplifiers" and "social amplifiers". Physical amplifiers include natural amplifiers and man-made amplifiers, whose functions are magnified or attenuated through social amplifiers. As this part focuses on food safety risks in public health incidents, only discusses "social amplifier" of risk is discussed here.

\subsubsection{Analytical Framework}

The social dynamics analytical framework of risk amplification used in this study portrays an intriguing risk landscape, where the information processing by individuals and organizations, institutional structure and responses, behaviors of social groups and individual activities together shape the social experiences, and ultimately affect the consequences of risk. Many of these consequences are not expected by risk managers. As shown in Fig. 3.1, risk is absolutely real, and is also determined by society and culture. When we study risks, we should no longer merely argue about "objective, real risks" or "subjective, distorted risks". Only when people consider the relationship between the world and themselves, the so-called risk is meaningful. The basic analytical framework of this study can be likened to the surface of a pond 


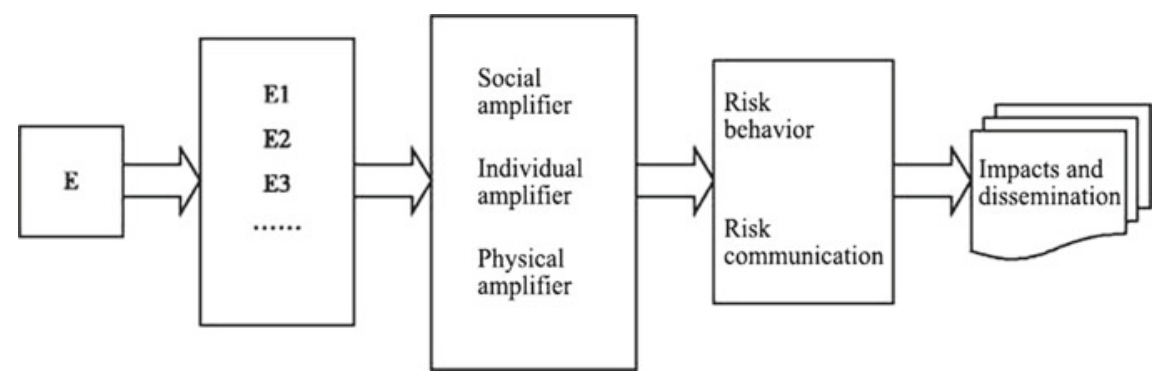

Fig. 3.1 Risk amplification and its potential impacts

rippling when a stone is thrown into it. As far as risk is concerned, those first affected are the direct victims or people who pay close attention to it; then the behaviors, communication and responses of different groups and individuals, not just the directly affect groups, may bring about new, second-level consequences; these consequences will in turn be perceived by other groups, and then another risk amplification process starts and may lead to third-level consequences. Such continuous amplification effects, in extreme cases, may penetrate into other sectors and remote areas, or even into social core values, and institutional and policy orientation.

\subsubsection{Research Methods}

\subsubsection{1 "Process-Event Study"}

The "process-event study" approach is a new attempt to get rid of the traditional methods of structural analysis or institutional analysis. It looks beyond the formal structure, organization and institutional framework of society and dives into the events and processes formed by social actions to shed light on social phenomena and social processes. This study no longer regards incidents as a result, but takes the evolution of incidents as a relatively independent explanatory variable for causal analysis. Causal analysis is not to simply pile up post-incident materials, but to describe the mechanisms of how the social consequences of incidents take shape, evolve and are mitigated, and highlight the process in which risks are explained, disseminated, exchanged, interpreted and controlled by various "amplifiers". This process demonstrates some important features of a particular incident, and reveals the complex relationship between different factors of the incident, and the social and cultural significance of unexpected changes as a result of the incident in different settings. In a word, the "process-event study" approach is chosen to analyze incidents because it can help to understand risk itself in the established social culture, and highlight the social construction process of risk while examining the characteristics of social and organizational structure. 


\subsubsection{Literature Research and Case Study}

Literature research is a research method to explore social behavior and social relations by collecting and analyzing materials in the form of texts, symbols, pictures and others. According to the purpose and nature of this study, we use "content analysis" and "secondary data analysis, two methods of literature research, to illustrate the social mechanism and process of risk communication. "Content analysis" mainly targets at information on the media, especially major newspapers, radio, television, and the internet, and the "consonance of media reporting" ${ }^{1}$ between them, so as to describe the content of risk communication of incidents objectively, systematically and quantitatively, and in particular, to shed light on the interpretative mechanism of risk representation through analyzing the changes in the quantity and content of relevant information after an incident. "Secondary data analysis" is mainly to study and analyze the existing data released by the governments and academic systems. This research mainly uses the official statistical data available on the "public opinion channel" of people.cn as the primary data, and connects in new and heuristic ways the scattered and isolated information about risk dissemination and amplification to recreate data, and thus draw new conclusions. Literature on incidents and risk communication provides the basic background and empirical support for this research, and analysis of media texts, and government and public decision-making and performance, among others, is all based on literature.

\subsection{Case Descriptions and Analyses}

\subsection{1 “Risk Amplifiers” of Food Safety Incidents}

\subsubsection{1 "Social Amplifiers"}

Food safety concerns the health of every person, so people pay close attention to the behaviors of the industry and can quickly detect and respond to relevant topics. Inevitably, they will choose some features and specific aspects of the incidents and interpret them based on their own understanding and planning, and then process theses interpretations and put them on their agenda. The organizations and groups that oversee and respond to the information serve as the "risk amplifiers" of food safety incidents. Among the most important risk amplifiers are the institutionalized governments, enterprises, and news media.

\footnotetext{
1 "Consonance of media reporting" refers to that if an incident or topic reported by a medium has certain influence, it will be rapidly covered by other media in similar ways. See: Elisabeth NoelleNeumann and Rainer Mathes. "The Events as Events and the Events as News: The Significance of Consonance for Media Effects Research". European Journal of Communication, 1987, 2 (4): $391-414$
} 


\section{(1) Quick response from the media}

The media make it easier to expose risks to the society. As the "uncertainty" of risk aggravates the eagerness and anxiety about information at every level of society, the media are endowed with important responsibilities for fighting risks, exposing risk and visualizing risks. In modern society, the media play an inherent role in supervision, and have the capacity of steering public attention. Especially, the authoritative media with official backing are better at affecting the public and enjoy greater public trust. Any incident, with the engagement of the mainstream media, will soon have an "amplification effect".

[Fuyang inferior milk powder incident] In 2004, two reports, one titled "The Calamity of Inferior Milk Powder in Fuyang" by Shanghai-based Dongfang Daily on April 16, and the other titled "Who Killed Those Infants: An Investigation in Fuyang Fake Formula Incident" by Xinmin Weekly on April 17, revealed the substandard infant milk scandal in Fuyang of Anhui Province. The two articles were soon reposted by official news portals such as xinhuanet.com, drawing high attention across the country. On April 19, an influential program of China Central Television (CCTV) reported the incident, and for the first time released the names of the infant victims, provoking strong indignation of the general public.

[Melamine-tainted milk powder incident] On July 30, 2008, Western Business Daily published an article titled "Half a Bottle of Kidney Stones in Eight-monthold Infants" by journalist Zhang Yuncai, which states that "too much calcium may lead to stones in the body of babies, which may be related to their milk powder". After the electronic edition of the newspaper published the article at 8:55 a.m., it was successively reposted by Tencent, Netease and xinhuanet.com between 8:55 and 11:11 a.m. On that day, more than 2000 netizens posted comments on Tencent.

On September 9, Lanzhou Morning Post reported that the kidney stones of fourteen babies suffering from in Gansu might be associated with long-term consumption of some brand of infant formula. After the report was released on the electronic version of the newspaper at 8:26, it was reposted by thirteen websites including Netease, Tencent, and Gansu Channel of xinhuanet.com by 6:33 a.m., September 10. On September 11, yahoo.com.cn published a report titled "Anonymity of Milk Powder Brand Suspected of Causing Kidney Stones in Infants Provokes Public Indignation”, drawing public attention to the producer of the problematic milk powder.

On September 11, a report by Jian Guangzhou of Dongfang Daily revealed that the brand of milk powder that might have caused kidney stones in fourteen babies in Gansu was Sanlu, which soon came under fire from the public. Major news outlets such as Sohu, Sina, Yahoo, Tencent and Netease reposted the article.

After September 11, a slew of domestic television and radio stations began to report that infants and young children suffering from kidney stones were fed tainted milk powder. On the evening of September 12, the scandal was for the first time broadcast in Xinwen Lianbo, a well-known, authoritative daily program of CCTV.

On September 13, Xinwen Lianbo announced that in response to the Sanlu contaminated milk powder incident, the State Council decided to initiate the Level-I emergency plan for major food safety incidents. From September 12-23, the daily 
program reported a total of 25 pieces of news on the incident, including five on September 17 alone.

All the mainstream media put in a lot of manpower and material resources to follow up on the major news event. The clues about the incident, after being sorted out and rearranged by the media, were presented to the audience. For a period of time, people were frequently bombarded with and became more sensitive to information related to the melamine-tainted milk powder incident. Many people also took action, such as requesting refunds and compensations.

\section{(2) Engagement of authorities}

Any individual or organization in social life can become a "risk amplifier". Because of their different positions and roles in social life, however, their roles in amplifying or attenuating risk signals vary widely. It goes without saying that in Chinese society, the government plays a bigger role than any other organization, and government employees play a bigger role than ordinary citizens. When government leaders and government employees participate as representatives of authority in the handling of incidents, their credible, institutionalized and organized actions will significantly amplify the risk signals.

\section{a. Instructions from senior officials}

All major incidents in China can get instant results once state authority steps in, and food safety incidents are no exception. After learning of the Fuyang infant formula scandal, then Premier Wen Jiabao gave three important instructions: first, thoroughly investigate into the sources, marketing channels and sales regions of the inferior milk powder, and provide appropriate medical treatment for the affected children; second, on the basis of finding out the facts, people concerned shall be held responsible, and those convicted of crime shall be severely punished according to law and be exposed; and third, food and drug safety would be the focus of the year's efforts to keep the market economy in order, so as to ensure the people's food safety and protect their health. According to the Premier's instructions, the State Council enjoined the State Food and Drug Administration, together with relevant departments and local governments, to set up a team to conduct comprehensive investigations into the incidents in Fuyang and other regions and deal with them in a timely manner. "Instructions" from leaders have high administrative effectiveness in China, and in particular, "instructions" from senior officials can reach government departments at all levels and give a boost to their administrative efficiency.

[Fuyang inferior milk powder incident] After Premier Wen gave instructions, a taskforce of the State Council immediately went to Fuyang of Anhui and formed a joint investigation team together with the provincial government of Anhui to find out and deal with the incident by combining administrative investigations and expert appraisals such as investigating the market, tracking the sources, conducting rural infant nutrition examinations, checking out the cases in hospitals, and testing the products. 
b. Intervention by joint investigation teams and attention from the WHO

For major food safety incidents that have huge influence, relevant departments of the State Council would generally set up joint investigation teams to investigate and deal with the incidents on site. With growing importance to its international image and social prestige, the Chinese government would communicate with the World Health Organization (WHO) on major public health incidents, and keep other member countries informed. This to a large extent accelerates risk dissemination of the incidents and expands the scope of their influence.

[Melamine-tainted milk powder incident] The General Administration of Quality Supervision, Inspection and Quarantine sent a team to the plants of Sanlu to find out the causes of the incident and conducted special inspections on similar products nationwide. The State Administration for Industry and Commerce strengthened supervision and inspection over infant formula. The Ministry of Health set up a taskforce to investigate and deal with the incident, conducted a comprehensive investigation on the potential effects on infants and babies across the country, and organized experts to develop treatment plans. The Ministry also required medical systems to timely report similar cases, and also informed the WHO and relevant countries of the situation.

c. Launch of the national emergency plan

In January 2006, China released the National Emergency Plan for Public Emergencies, and a series of specific plans as a response to all kinds of emergencies. After the SARS outbreak in 2003, China accumulated certain experiences in responding to public health emergencies. The massive melamine-tainted milk powder incident turned out a good opportunity to test the food safety emergency plan.

[Melamine-tainted milk powder incident] On September 13, 2008, the State Council initiated the Level-I emergency plan for major food safety incidents, and set up an emergency response team led by the Ministry of Health and composed of the General Administration of Quality Supervision, Inspection and Quarantine, State Administration for Industry and Commerce, Ministry of Agriculture, Ministry of Public Security, the State Food and Drug Administration, and provincial government of Hebei.

The national health system and medical professionals provided screening and diagnosis services and free medical treatment for the affected infants and young children. All of the ten-plus national testing centers within the quality supervision, inspection and quarantine system worked 24 hours a day to test all infant formulas on the market, and local quality supervision, inspection and quarantine departments and testing systems were required to extend the scope of supervision and inspection to all dairy products.

The State Administration for Industry and Commerce, together with relevant departments, sealed up 2,176 tons of in-stock infant milk powder of Sanlu Group, recalled all of its infant milk powder products from the market, and destroyed tens of thousands of tons of tainted milk powder under the supervision of the quality supervision, inspection and quarantine departments. 
On September 14, the Ministry of Agriculture announced to conduct fresh milk quality safety inspections in fifty targeted counties of Inner Mongolia, Heilongjiang, Henan, Hebei, Shandong, Shaanxi, Xinjiang, Beijing and other major dairy-producing regions. The localities would also carry out such inspections.

The public security authorities inquired, investigated and collected evidence from the criminal suspects in an effort to solve the case as soon as possible. On the basis of solid evidence, those involved were transferred to the procuratorial authorities.

The fact that the State Council immediately set up a taskforce and initiated the Level-I emergency plan for major food safety incidents reflects that the government attached high attention to the incident and was determined and took measures to deal with it. It should be noted that the intervention of state authority heightened the attention of the general public, making them believe that the incident was far more serious than they previously thought. When the signal of "instructions" from the top leaders published by the media became a focus of conversations among the public, the risk property of the melamine-tainted milk powder incident was exacerbated.

\section{(3) Large companies' response}

Companies are production organizations of society and conduct close material and information exchanges with others. In particular, the products of large food producers have a bearing on public health, and the reliability of their production technology and the quality of their products draw high attention from all sectors of society, especially the media and the quality supervision and inspection authorities. Once companies are involved in public safety incidents, whether they try to cover up the problems and shirk responsibility, or clarify fallacies and rebuild their brand, they will inevitably attract wider public attention and media coverage, which will take risk-related information to a new level and speed up the public's perception of risks.

[Fuyang inferior milk powder incident] Due to some mistake of the Disease Prevention and Control Center of Fuyang, Sanlu infant milk powder was considered "substandard" after tests. This test result appeared in Yingzhou Evening News on April 22, 2004 and was reposted by other domestic media. As a result, Sanlu milk powder was removed off shelves and sealed up around the country. From April 22 to 26, the sales of Sanlu plunged 80\%, causing a loss of RMB20 million. On the day when the test result was announced, the senior executives of Sanlu Group immediately got in contact with relevant departments of the local government. Then the investigation taskforce of the State Council held a press conference to clear up the situation. Later, Sanlu Group, together with a dozen well-known dairy producers in China, released the dairy industry integrity declaration in a number of cities, pledging that they would never produce and sale substandard dairy products.

[Melamine-tainted milk powder incident] On September 9, 2008, Lanzhou Morning Post reported that fourteen infants in Gansu suffering from kidney stones were fed the same brand of infant formula. The report was quickly reposted by other news media, including websites. On September 11, an article by Jian Guangzhou of Dongfang Daily revealed that the fourteen infants were all fed milk powder produced by Sanlu Group, which came under national spotlight again in negative news. 
At 10:00 a.m. on the same day, Sanlu Group declared via people.com.cn that as a well-known milk powder brand, it produced qualified products in strict accordance with national standards, and there was no evidence linking the kidney diseases of those infants with its products.

At 20:50, the Ministry of Health announced that after investigations, it was strongly suspected that the infant formulas produced by Shijiazhuang Sanlu Group Co., Ltd. were contaminated by melamine, which can lead to stones in the urinary system.

At 21:30, Shijiazhuang Sanlu Group Co., Ltd. announced a recall, saying that after self-inspections, it found that about seven hundred tons of infant milk powder that went to market before August 6, 2008 was tainted by melamine, and to be responsible to consumers, it decided to recall all these batches.

On September 13, Gao Qiang, Party chief of the Ministry of Health, pointed out at the press conference that the "Sanlu infant formula incident" was a severe food safety incident.

On September 17, the General Administration of Quality Supervision, Inspection and Quarantine conducted emergency inspections on the use of melamine in infant formulas around the country, and later released the interim inspection results showing that sixty-nine batches of products produced by twenty-two enterprises, including large dairy enterprises like Mengniu, Yili and Shengyuan, contained varying amounts of melamine.

It is neither a coincidence nor a plot that Sanlu, a well-known dairy producer, was the leading role of both food safety incidents. It is the company itself that was the main factor in the incidents. In particular, companies as large as Sanlu inherently have spotlight effects, and consequently, any relevant information can be focused on by the media and perceived by the media at a higher speed. Public tip-offs and media reports soon made dairy quality a risk topic in society, and all brands related to substandard products came under fire from the public. Then people turned their concern about food safety into actions to request refunds and compensations and boycott home-made dairy products.

\subsubsection{2 "Market-Based Amplifiers"}

Nowadays, many kinds of foods are mass-produced, especially milk powder which requires relatively high technology. Market plays an indispensable role throughout the process from the production of raw materials to sales of products. Therefore, the "risk amplifiers" of these products basically coincide with the organizations along relevant industry chains ranging from the production, processing and transportation of raw materials to the production, transportation and sales of products. In other words, the reason why food safety risks can spread quickly and widely is the high degree of integration of trade, industry and agriculture. In the melamine-tainted milk powder incident that caused huge harm and severe social impacts, the "market-based amplifiers" mainly include the following organizations. 


\section{(1) Melamine producers}

In the 2008 milk powder scandal, the chemical product blamed for contamination is called melamine, also known as "protein powder". In China, most melamine is directly sold to factories manufacturing acrylic molds, decorative sheets and the like, or to qualified distributors. Melamine residues are sold to distributors and mainly used by the feedstuff industry.

\section{(2) Chemical product traders}

After high-temperature disinfection and processing, these traders turn melamine residues into "protein powder". Melamine residues, which contain 20-30\% protein content, are sold at RMB350-RMB700 per ton; in contrast, "protein powder" contains as much as $60 \%$ protein, and can be sold at RMB3,600-RMB3,800 per ton.

(3) Protein feed suppliers

After buying "protein powder" from chemical product traders, protein feed suppliers turn the powder into protein feeds after simple packing. Generally, these suppliers set up plants in rural areas or small towns and locate their offices in cities, and recruit marketing personnel to sell products.

\section{(4) Feed producers}

Protein feed suppliers sell protein feeds to feed producers, which must keep protein content in feeds within a set range. The higher the content of crude protein, the more expensive the feeds. Therefore, in pursuit of higher profits, some feed producers add the less expensive "protein powder" to reduce costs.

(5) Numerous dairy farmers and milk collection depots

A large amount of raw milk used by dairy companies is purchased from dairy farmers or in the mode of "companies + farmers". Dairy farmers feed cows with feeds that contain "protein powder", and provide fresh milk to milk collection depots, which then supply the raw milk to dairy companies.

\section{(6) Dairy product companies}

In the 2008 melamine-laced milk powder scandal, twenty-two dairy product companies were exposed by the General Administration of Quality Supervision, Inspection and Quarantine, including Sanlu Group of Hebei, Yashili and Gucheng of Shanxi, Yili and Mengniu of Inner Mongolia, Qingdao Shengyuan, Shanghai Panda Dairy, Jiangxi Bright Dairy, Baoji Huimin, Torador, and Nanshan Dairy of Hunan. Some of them were well-known large companies in China.

(7) Dairy product wholesalers and retailers

Wholesalers sell products and services to other resellers, retail enterprises and manufacturing enterprises rather than end users. Retailers sell products and services directly to consumers. According to their scope of business, retailers can be divided into general stores, specialized stores, supermarkets, large department stores, and 
superstores. Retailers directly serve final consumers, so they are scattered in different places depending on the population and market status. In the milk powder scandal, contaminated milk power entered numerous households through a vast network of retailers in urban and rural areas.

\subsection{2 “Risk Amplification Mechanism"}

\subsubsection{Exposure of Incidents and Risk Attributes}

\section{(1) Exposure of risks}

With inadequate regulation, some public health incidents come to the surface accidentally. It can be found after careful analysis that these contingencies are exactly the key inducers of risks and the spread of their consequences.

[Fuyang inferior milk powder incident] On April 16, 2004, a report titled "The Calamity of Inferior Milk Powder in Fuyang" by Shanghai-based Dongfang Daily claimed that the "big-headed" infants died of long-term consumption of substandard infant formula. The report was reposted by major web portal Sina and then by other media organizations, and attracted attention from leaders of the central government. At this time, the milk powder scandal came into public view.

[Melamine-tainted milk powder incident] Before the report about the infants with kidney stones on September 11, 2008, the contamination of Sanlu milk powder was a secret. Although similar cases appeared successively in Gansu and other regions after the first infant with kidney stones was diagnosed in Nanjing in March 2008 and complaints about problematic milk powder were posted on the website of the General Administration of Quality Supervision, Inspection and Quarantine, the incident didn't draw sufficient attention from relevant departments and individuals.

It didn't get wide media coverage until early September 2008 when Lanzhou Morning Post published the conversation with Zhang Wei, director of the urinary surgery department of the PLA No. 1 Hospital, and revealed the cases of the affected infants. The report was soon reposted by major news websites. On September 11, a report by Dongfang Daily pointed to Sanlu, and the truth of the milk powder scandal was finally exposed. On September 12, the police of Shijiazhuang summoned seventy-eight suspects, and the General Administration of Quality Supervision, Inspection and Quarantine launched a national investigation.

(2) Basic characteristics of food safety incidents

a. Threat to health and life

There are strict requirements on food safety. Food may not contain any substances or unsafe factors that may harm or threaten people's health, lead to acute or chronic poisoning or infectious diseases, or pose any hazards to the health of individuals and their offspring. Such stringent safety requirements stem from the special relationship between food and health. Food is essential to the metabolism in the human body. If 
there are toxic and harmful substances in food, it will damage the normal function of the human body and even endanger the life. After all, nothing can cause greater anxiety than the threat to people's life.

From May 2003 to April 2004, thirteen children died of malnutrition symptoms due to inferior milk powder in Fuyang alone, with a mortality rate of $7.6 \%$. The melamine-tainted milk powder incident was even more severe. From September 12 to $8: 00$, September 17,2008 , a total of 6,244 clinical cases were reported around the country, and 1,327 children remained in hospital for further observation and treatment. Among the clinical cases, eighteen suffered from acute respiratory failures, leading to three deaths.

\section{b. Direct victims of incidents}

Unqualified food can directly affect the human body, and infants are more vulnerable to the hazards due to their relatively low immunity. "Big-headed dolls" and "kidney stone babies", the victims of the milk powder scandals, were mostly infants under one. Their symptoms included overly large heads, disproportionate bodies, growth retardation, and different degrees of kidney dysfunction and stones in the urinary system. Heart-wrenching pictures of these infants released by the media and the suffering of these innocent victims provoked public compassion for the young lives and indignation at the outrageous lawbreakers.

\section{c. Sensitivity of incidents concerning people's livelihood}

Issues about people's livelihood, especially rural issues, have for years been the focus of attention of the government and the public. The CPC Central Committee has stressed time and again that no organization or individual is allowed to harm the interests of farmers and has taken various measures to promote rural development. In China, "people's livelihood" and "rural issues" are not just economic issues, but more importantly, they concern political stability. For any incidents that have baneful influence and seriously harm the vital interests of the people, all sectors of society, especially the central government, are bound to step in. At a time when the underprivileged rural areas needed more support from urban areas, the damage of inferior and toxic milk powder to the health of infants in urban and rural areas undoubtedly increased the sensitivity of the incidents.

\section{d. Wide influence}

The development of the food industry depends on the improvement of modern business and circulation systems. Although the highly complicated social division of labor can drive social progress and improve people's quality of life, the omnipresent modern marketing system also facilitates the spread of counterfeit and inferior products. Once loopholes appear in the complex industry chain, risks will penetrate into numerous households through the modern systems of trade, industry and agriculture, posing a threat to everyone's life and health. It is the highly integrated but extremely vulnerable production and marketing chains of the food industry that have expanded the influence of risks. 


\subsubsection{Behavior Choices in Risk Amplification}

Social amplification and attenuation of risk are pronounced in food safety incidents. Social amplification of risk will lead to additional institutional responses and protective actions, while in the case of social attenuation of risk, governments, organizations and individuals will reduce protective actions. Whether the organizations or individuals act to amplify or attenuate risk signals depends on their perception of the incidents and their interest considerations. Extra demands will give rise to "excessive action", which, like "behavioral dislocation" associated with risk attenuation, will result in many unexpected social consequences.

\section{(1) Overreporting by the media}

Overreporting is mainly reflected in the stigmatization of domestic milk powder. Once any individuals, organizations or incidents are labeled "alien", "unpopular" or "dangerous" and such labels are constantly reinforced by the media, they will be repulsed by more people. This process is called stigmatization. The media can play different roles, such as objectively covering, beautifying or stigmatizing what they report, depending on the perspective chosen by the media and the expression of interests. When it comes to food safety incidents, the media often overreport, which practically leads to stigmatization of the incidents and people or organizations concerned.

Stigmatization of milk powder. Milk powder was the "protagonist" of the Fuyang milk powder scandal. The specific process of its stigmatization can be seen from the modifiers of milk powder used by the media. Initially, Xinhua News Agency reported that the infants had fallen victim to "non-nutritive milk powder", to which Dongfang Daily and Xinmin Weekly referred as "shell milk powder" and "fake milk powder". With the articles being reposted and quoted by other media, there were more terms blaming the inferior quality of milk powder, such as "poisonous milk powder", "black-heart milk powder", or "killing milk powder". Later, law enforcement authorities around the country found more unqualified milk powder, and because some contained excessive ingredients that may turn into carcinogens, some media called it "carcinogenic milk powder". From "non-nutritive milk powder" to "carcinogenic milk powder", the media had heightened the hazards of inferior milk powder to an appalling level.

Runaway numbers. With the continuous stigmatization of milk powder, the numbers about unqualified domestic milk powder reported by the media also mounted. On April 20, 2004, the provincial government of Anhui published a list of forty-five types of inferior milk powder found in Fuyang. On April 23, a Beijing media reported that fifty-five types of inferior milk powder were involved, and some media even claimed that there were hundreds. The number of brands and amount of inferior milk powder were horrifying in media reports, which professed that the amount of unqualified milk powder found in Guangdong, Henan, Hebei, Sichuan and elsewhere reached tens of thousands each. In fact, in early May 2004, the General Administration of Quality Supervision, Inspection and Quarantine published a list of thirty enterprises whose products had been qualified as shown in spot checks, and made up $80 \%$ of 
the total milk powder output in China, indicating that the quality of milk powder produced by domestic formal enterprises was stable. Such authoritative information from state authorities, however, carried little weight in comparison with the "craze to expose scandals" set off by the media. The principle of "objectivity and truthfulness" that news reports should follow was shattered by the stigmatization of domestic milk powder by some media. Risk signals were amplified over and over again in media reports, and a large amount of information, accurate or not, was received and reorganized by the general public. Media exaggeration of risks may conceal rational and critical voices, and generate some kind of interest-oriented dominant discourse that can turn the public into a passive audience and risk communication into superficial risk perception, resulting in the spread of social panic and distrust.

(2) Risk attenuation behavior of local governments

After the exposure of incidents, local governments usually will take steps to deal with the imminent crisis. Their approaches may be proactive and targeted, or passive and circuitous. Subjectively, local governments try to minimize the negative effects of the incidents, and often take various measures to attenuate risk signals. In the above-mentioned two milk powder incidents, the attitudes and behaviors of local governments were mostly positive; they timely released relevant information and conducted risk communication with the news media and the public. Still, under pressure of public opinion and in face of the unquestionable "accountability" mechanism of state authorities, a few local government departments and their responsible persons somewhat got into a muddle.

"False dismissal" farce. In the Fuyang milk powder scandal, dozens of officials were held accountable. A county-level bureau of industry and commerce in Fuyang announced the decision to dismiss two employees on the ground of neglect of duty. Later, however, it was founded that the decision was never implemented. This "false dismissal" incident implies that in fact of sudden risks, some local governments got panic-stricken, and attempted to alleviate the pressure of accountability by resorting to the traditional strategy of "giving up a pawn to save a castle". Unfortunately, such actions can only aggravate risk dissemination, because what a responsible person said or did will inevitably touch the "nerve" of the "sensitive" public at that time, triggering multi-level spread of risk signals.

Embarrassing "free treatment". The investigation team of the State Council suggested the municipal government of Fuyang take measures to improve the health status of infants with mild and moderate malnutrition in an all-round way. The municipal government of Fuyang also pledged to provide "free treatment". Yet the promises made under intense pressure turned out to be unreliable, as reflected in the local government's Guidelines on the Treatment of Infant Malnutrition Caused by Inferior Milk Powder. The Guidelines does not provide normal reference values for judging malnutrition or specify how laboratory test data support the diagnosis malnutrition. The vague assessment standards made it difficult to identify the responsibility, and the consequent buck-passing led to a delay in treatment for some young patients who were in fact entitled to free treatment. 
Cover-up and prevarication. In the melamine-tainted milk powder incident, the attempts to cover up before the incident was exposed, together with the prevarication and downplaying after the incident occurred, constituted the typical "risk attenuation" behaviors of local government departments. The senior executives of Sanlu Group made two written reports to the municipal government of Shijiazhuang on August 2 and 29, 2008, respectively. After receiving the reports, the municipal government immediately sent a taskforce to Sanlu Group to deal with relevant issues. A month later, however, the government neither required Sanlu Group to recall the products and stop production, nor reported the major food safety incident to higher authorities as required. Consumer complaints began to surge in March 2008, nearly half a year had passed before the government initiated the Level-I emergency plan for major food safety incidents on September 13, missing the best time to deal with the crisis.

Inappropriate actions of local governments. Local governments may take inapt approaches to dealing with the incidents because of the lack of experiences or in consideration of medical costs and social costs. Whatever the reason, the local governments' "circuitous" action strategy is intended to attenuate the risk signals and prevent the incidents from escalating, but truth cannot be concealed forever, and the attempts to cover up can backfire, resulting in greater adverse effects on a larger scale.

\subsection{3 “Ripple Effects” of Food Safety Incidents}

The "ripple effects" of food safety incidents like the milk power scandals are first reflected in the decline of public trust in the enterprises involved. For example, the inferior milk powder incidents dented the consumers' long-time trust in famous domestic brands. Second, food safety incidents can have influence on the local economy, resulting in a decrease in the enterprises' assets and recession of the industry. Third, food safety incidents can also bring political and social pressure and prompt the public to make more political demands. In addition, food safety incidents can reduce the public's trust in the quality inspection and supervision capacity of the enterprises and authorities, and may affect other industries, departments and regions with similar problems.

\subsubsection{Judicial and Administrative Effects}

From the time the "big-headed babies" were first reported to August 2005, four dens that produced and sold fake milk powder in Fuyang were uncovered, and fortytwo suspects were put in detention. Among them, twenty-four people were arrested with the approval of the procuratorate, and five defendants were later sentenced to four to eight years. According to the regulations on the CPC disciplinary actions and the Provisional Regulations on Public Servants, as well we the suggestions of the Ministry of Supervision, the provincial government of Anhui imposed severe 
administrative and disciplinary punishments on the mayor of Fuyang and chiefs of industry of commerce, health and other municipal departments.

The melamine-tainted milk powder incident in 2008 had even more significant judicial and administrative effects, and extremely severe punishments were inflicted on Sanlu Group. The principal responsible persons were sentenced to imprisonment for life, given death sentence with reprieve, or even put to death; twenty-four persons of the provincial and municipal Party committees and governments were subjected to severe penalties.

\subsubsection{Economic Losses and Influences on Industries and Regions}

After the Fuyang milk powder scandal was exposed, the industry and commerce administrations of twenty-six provincial regions successively smashed a handful of dens that produced and sold fake milk powder, and sealed up batches of substandard milk powder. The sales of domestic milk powder plunged. In May and June 2004, the sales of domestic milk powder dropped $25 \%$ compared to the same period in the previous year. According to the Dairy Association of China, the incident had "disastrous consequences" for the emerging dairy industry of the country, in that it not only came as a terrible blow for domestic dairy companies, but also undermined the consumers' trust in domestic milk powder. In contrast, the sales of imported milk powder surged about $20 \%$ in the two months after the incident was exposed. The melamine-tainted milk powder incident in 2008 had even far more extensive and profound influences than general food safety incidents. In September 2008, Sanlu Group was ordered to stop production and sales. On December 18, 2008, the Shijiazhuang Intermediate People's Court decided to accept the application of the creditor Heping Road Branch of Shijiazhuang Commercial Bank for bankruptcy liquidation of Sanlu Group. By December 31, 2008, Sanlu Group, which was unable to pay its debts, was declared bankrupt according to law.

The effects of the incident did not stop after the bankruptcy of Sanlu Group, but spread to other areas.

(1) The dairy industry suffered huge losses. With the reorganization of Sanlu Group shortly after its insolvency, the brand, which was worth up to tens of billions yuan, disappeared overnight. The whole domestic dairy industry suffered a terrible blow. The General Administration of Quality Supervision, Inspection and Quarantine revoked the "famous milk brand" certification mark of Mengniu, Yili, and Bright. The domestic dairy industry saw a substantial decline in business performance. The market value of major dairy companies shrunk dramatically by more than RMB21 billion in total as share prices plummeted.

(2) Agriculture, animal husbandry and other food industries were seriously affected. For example, the egg industry saw a sharp reduction in egg prices. The daily wholesale volume of Guangzhou Chatou Egg Market, the country's largest egg wholesale market, dropped from 1,500 to 500 tons, down two-thirds. 
(3) The entire food industry chain slumped. Under the impact of the melaminetainted milk powder incident, many food enterprises were shut down. For example, the sales of cellulose ether, an important additive in the food industry, plummeted, and the prices dropped by $30-50 \%$.

\subsubsection{Contribution to the Risk Governance Mechanism}

On February 28, 2009, the Seventh Session of the Standing Committee of the Eleventh National People's Congress adopted the Food Safety Law, which came into effect on June 1. Food safety accidents have prompted the country to improve the institutional setup and the risk assessment system, which is mainly reflected in the following aspects.

(1) The State Council set up the Food Safety Committee, a high-level body responsible for coordinating and guiding food safety supervision.

(2) The responsibilities of departments relevant to food safety supervision of the State Council were clarified. The quality supervision, industry and commerce, and food and drug authorities shall supervise and administrate food production, food circulation and catering services in accordance with the Food Safety Law and the responsibilities prescribed by the State Council. The health authorities are responsible for coordinating work on food safety, including assessing food safety risks, setting food safety standards, releasing relevant information, certifying food testing and inspection agencies, drawing up inspection regulations, and organizing investigations into major food safety incidents. In the case that agriculture, quality supervision, industry and commerce, and food and drug authorities discover any food safety incident or receive relevant tips, they should notify the health authorities immediately.

(3) Food safety risk monitoring and evaluation has been strengthened. A complete food safety risk monitoring system, including the formulation, release, implementation and adjustment of food safety risk monitoring plans, has been put in place, to better monitor foodborne diseases, food contamination and harmful factors in food. A sound food safety risk assessment system covering the launch, specific operations, and use of results of food safety risk assessment has been developed. When food safety hazards are found through food safety risk monitoring or tip-offs, risk assessments on biological, chemical and physical hazards in food and food additives will be conducted.

(4) Supervision over food additives has been tightened. The health authorities shall, in accordance with the results of food safety risk assessment, timely adjust the varieties, scope of use and dosage standards of food additives, and ensure that no other chemicals than food additives or any substances harmful to human health are used in food production.

(5) Food inspection has been strengthened. It is made clear that food safety supervision and administration departments may not exempt institution from food inspection. 
(6) The food recall system has been improved. When a food producer discovers that their food products are below food safety standards, they shall immediately stop production, recall the products on the market, notify relevant traders and consumers, and put the recall and notification on record. If a food producer or trader fails to recall products or stop production in accordance with the relevant regulations, quality supervision or industry and commerce authorities above the county level can order them to do so.

(7) Management of food advertisements has been tightened. Food advertisements shall be true and legal and shall not claim or imply in any form that the food can prevent or treat diseases. Food safety supervision and administration departments or food inspection agencies, food industry associations, and consumer associations shall not recommend any kind of food to consumers by advertising or other means. If the legitimate rights and interests of consumers are harmed because of the food recommended by organizations or individuals in false advertising, the said organizations or individuals shall be jointly and severally liable with the food producers and traders.

(8) Management of small food production or processing workshops and food vendors has been strengthened. Local governments at or above the county level should encourage and support small food workshops to improve their production conditions, and food vendors to operate in fixed places such as markets and stores. To engage in food production or trade, a small food production or processing workshop or a food vendor shall meet the food safety requirements of the Food Safety Law suitable for its production or trade scale and conditions, and ensure that the food which it produces or deals in is hygienic, nontoxic, and innocuous. The food and drug authority shall strengthen supervision and administration over them.

\subsection{Main Conclusions}

\subsubsection{Main Factors Influencing Public Perception of Health Risks}

The judgement, assessment and attitudes of people based on uncertainty in a particular context are risk perception. In everyday life, people receive and process all kinds of information, including information concerning the potential consequences of future activities and events. Based on the received information, individuals or organizations will form their own opinions and attitudes towards the sources and consequences of risks, and act accordingly. According to this logic, what an emergency brings is the information about health hazards. Once the threats posed by physical and social impacts to what people value, such as health, life and property, cannot be controlled effectively, people's fear will become so intense that it will result in a series of chain reactions. In this sense, risk perception is not so much 
a product of personal experiences as a product of social interactions. Our research shows that in emergencies with physical hazards, the public's risk perception and the occurrence of social panic are directly related to the following attributes of risk.

\subsubsection{Degree of Familiarity}

The physical hazards of emergencies are mostly objectives and facilities people are familiar with. When people get to know that an everyday object contains substances that harms their health or even can cause cancer or the infrastructure they depend on becomes a hazard, the mixed feelings of familiarity and unfamiliarity will greatly raise their sense of panic. The influence of the degree of familiarity on risk perception can be illustrated in the following aspects.

\section{(1) Invisibility}

In general, people find it harder to accept invisible risks than visible risks because they tend to become accustomed to familiar, visible risks but overestimate unfamiliar, invisible risks. For example, the food additives or chemicals in food are quite unfamiliar to the general public, but they are added to food and water such as infant formula and tap water, which people are all familiar with. Once they are described as a threat to health, lack of knowledge of how they are produced, spread and how hazards are caused will significantly aggravate the public's fear and anxiety about the risks. Most people would shudder to associate familiar, indispensable food and water with complex, toxic chemicals.

\section{(2) Degree of exposure}

When people feel or think they are at risk and they and their families are exposed to a dangerous environment or toxic substances, a natural response for most people is fear, which will intensify their assessment of other aspects of risks. Especially in the areas of food hygiene or workplace safety which are directly related to people's lives, they will be even more vigilant against those chronic, potential health hazards. For example, when harmful substances (melamine) directly or indirectly appear in milk powder for infants and young children, the public would feel that their innocent children were exposed to risks, leading to fear that no one could be free from a toxic environment.

\section{(3) Difficulty in detection}

Because of their confidence in life experiences, people usually use their everyday life skills to detect certain dangerous situations and substances, and gauge the degree of danger through "emotional heuristics" to avoid danger. If risks themselves are obvious and conspicuous or the harms they cause are direct, people can discover some clues of the risk signals with daily knowledge and human sense organs, and then anxiety about risks will be greatly alleviated. As far as food is concerned, however, it is often difficult to distinguish the beneficial and harmful substances. For example, many harmful chemicals can be easily dissolved in drinking water and 
cannot be detected by human sense organs. When people are unable to detect whether food additives are harmful by "looking" or "smelling", that will inevitably result in anxiety and panic.

\subsubsection{Controllability}

Controllability is about what measures people can take to prevent themselves and their families from risks and to reduce losses. Whether people can control the results of interactions between their behavior and objects is a defining factor for their interests, health and safety. The influence of controllability on people's panic and anxiety about risks can be explained in the following three aspects.

(1) Availability

People tend to think that things easier to produce and obtain are more liable to be misused. Based on this logic, the general public believe that goods easy to produce and widely used are mostly cheap and involve safety hazards. The development of the chemical industry makes it easier to produce food ingredients, which therefore become more prone to misuse. Chemicals such as melamine and benzene are easy to produce and have evident chemical effects, so the controllability of risk is greatly reduced.

\section{(2) Complexity of risk systems}

Isolated risk events are considered to be controllable and less harmful. For this reason, people's risk perception of them is relatively moderate. In contrast, systematic risks involving complicated chains of production, processing, transportation, storage, sale and use are generally thought to be more difficult to control. It is found that there is a positive relationship between the length of chains of risk systems and the urgency of risk perception.

\section{(3) Specialization of risk control}

Because of the complexity of modern society, it is necessary to establish specialized agencies for risk control, draw up detailed risk control regulations, and implement strict measures to protect people's safety and enhance public trust. The more specialized risk warning and control, the more likely it is to alleviate people's fear. On the contrary, if the agencies, regulations and measures for risk control in a more complicated society are not in place or believed by the public to be flawed, that may result in the spread of perceived risk. Chemicals like melamine and benzene are not supposed to appear in food and drinking water, let alone be used as food additives. But such things have been happening. As a result, the public become more concerned about food safety and is inclined to think that the authorities conduct inadequate supervision over the food and health industry or even are negligent in doing so. The fact that relevant departments frequently issue notices on strengthening supervision is tantamount to telling the public that specialized efforts to control such problems are not sufficient, thus leading to the spread of panic about food safety. 


\subsubsection{Disaster Tendencies}

Toxic, carcinogenic, and rapidly diffusible substances that are hard to prevent and can stay for a long time will undoubtedly exacerbate people's fear and sense of impending disaster.

\section{(1) Lethality}

Foreign research shows that people tend to overestimate the risks of incidents with low probability but high mortality, and incidents that are instantaneous and destructive. ${ }^{2}$ Fatal incidents, substances or environments are most likely to cause risk perception and panic behavior. For an ordinary person, nothing is more precious than their life, and nothing is more frightening and agitating than a threat to health. The high pathogenicity and high mortality of risk events are the most significant signals for people in risk interpretation. Many misused additives are prohibited substances, which are medically categorized as Group-II carcinogens and can endanger human health. To the eye of most people, cancer means death, and perception of cancer risk will overpower rational analysis and response.

\section{(2) Wide distribution}

The spatial distribution of risk events also has influence on risk perception. In general, the spatial distribution of environmental pollution, ecological pollutant discharge and the like show particular characteristics due to the restrictions of natural conditions. Such health-threatening substances are transmitted through wind, air and natural water sources, and become less harmful as they spread farther. In contrast, the substances that gradually affect human health through metabolism of the human body are not apt to change with the natural environment. Moreover, manufactured food is stored and sold via a wide range of channels. Problematic food can enter various supermarkets, stores and markets in urban and rural areas through the modern logistics system, and then be bought by numerous households. Thus, people feel that these harmful substances can penetrate through so extensive channels that it is unlikely to keep away from them.

\section{(3) Time lags}

The time lag of risk perception is related to its spatial extensiveness. If a risk event affects a large area in multiple ways and has long-lasting impacts that can hardly be eliminated in the short term or even be harmful to future generations, then it is more likely to cause public anxiety and fear. Modern medical research suggests that with the change in the living environment, especially the exposure to a harsh environment or long-term exposure to dangerous substances, the internal physiological environment of the human body will also change, and such accumulated change will lead to genetic disorders and eventually an irreversible genetic disaster, even posing a threat to the health of their offspring. Such risks will gradually emerge by means of

\footnotetext{
${ }^{2}$ Paul Slovic \& Ellen Peters. The Importance of Worldviews in Risk Perception. Risk Decision and Policy, 1998, 3 (2), pp. 165-170.
} 
metabolism that features subtle and insignificant physiological changes. This is the case for substandard, unsafe food and harmful substances discharged by enterprises, which are believed to alter the body's cellular structure and metabolic processes and gradually cause diseases. As people have extreme fear about such intangible but pernicious substances, the exposure of their insidious, gradual effects and the possibility of causing long-term consequences and hereditary diseases will significantly elevate the perceived level of risk.

\subsubsection{Knowledge}

Due to the lack of professional knowledge and discernment, people tend to follow like sheep and panic in face of risk warnings.

\section{(1) Expert knowledge}

Since the Enlightenment in the 17th and 18th centuries, the worship of science and technology has become an irresistible global trend. The discourse power of scientism has spurred public trust in all kinds of expert knowledge. Expert knowledge, a representative of science, is regarded as a safety valve for warning against and preventing risks. The inertial thinking of "science and technology can solve all problems" has led the public to blindly believe in the ability of experts. If the experts claim that an particular risk can be avoided and solved, then it generally won't cause social panic, and the perceived level of risk is relatively low to most people; on the contrary, if the experts say that "the causes are unknown" or "the crux of the problems has not been found", the incident is often perceived by the people as potentially risky, and the perceived level of risk will be higher. In face of the opinions of different experts, the public feels that things are not so simple and the risks are far beyond what they can control, so they had better be cautious. This will unavoidably lead to panic.

\section{(2) Personal knowledge}

If the public has a comprehensive knowledge of a particular risk event and can objectively perceive the outcomes of the event, receive information from multiple rather than single aspects, and rationally view and assess the impacts of the event on themselves and the society, they can make appropriate behavioral responses, or even engage in some public interest activities to eliminate or reduce the impacts on the whole society. In practice, however, the public is convinced that they do not have the specialized knowledge and analytical ability of technical experts. Therefore, when a risk event occurs, few people can respond based on rational analysis and careful judgment, whereas most people simply "go with the tide" and "spread false information". This will profoundly affect people's psychological and behavioral responses in risk situations. 


\subsubsection{Stigmatization in Food Safety Risks}

Among the consequences of a risk or crisis is more or less stigmatization, a phenomenon in which relevant objects, people, systems, environments and even institutional culture are labeled "harmful", warning others to keep away. At the same time, stigmatized objects can arouse repulsion and rejection, which, if escalating, may cause social panic and even trigger a public crisis. After the melamine-tainted milk powder incident was exposed, the dairy boycott as a result of a few types of "problematic milk powder" swept through the food industry, and creditability of all dairy-related products, production and marketing enterprises, and regulatory arrangements were widely questioned. Consequently, the dairy enterprise responsible, which had performed well for decades and was worth over RMB10 billion, collapsed overnight; the "toxic milk powder" led to property depreciation and compensation litigation, and other enterprises were also disparaged and boycotted. It can be seen that the consequences of stigmatization go far beyond the direct damage to people's health or living environment, and exceed the technical capacity of the previous management mechanism, posing a greater challenge to those responsible for risk and crisis management.

\subsubsection{The Nature and Characteristics of Stigmatization}

\section{(1) The nature of stigmatization}

Stigmatization is a process in which the society attaches a derogatory or abusive label to certain individuals or groups, thereby subjecting them to social injustice and other consequences.

Due to the concerns of modern society about growing risks, the objects being stigmatized have extended from groups or individuals to anything considered dangerous, including technologies, organizations, and even institutional settings. Stigmatization in incidents can be understood in the following three aspects.

First, stigmatization can dent the image. Stigmatization is not just about causing casualties and property losses, but can damage the image of things, people or systems by tagging them as "alien" or "dangerous", which can lead to unimaginable cultural, economic and political consequences.

Second, stigmatization derives from the failure to ensure people's right to know. Stigmatization occurs only when information about key people or things is blocked and the truth is "distorted" to such an extent that their reputations are disparaged by the public, bringing irrepressible fears. When people's demands for explanations of some ambiguous facts are not satisfied, the objects, people or systems that cause such ambiguities will become the focus of the public, and will be redefined and reinterpreted, and given a negative tag. Anxiety, fear, and ultimate disappointment will pervade the society, and the extreme tension will erode the foundation of rational judgment, prompting people to find a "scapegoat" to alleviate fear. 
Third, stigmatization reflects social concern. Stigmatization in fact reflects the widespread concern about some risks in society, and is often used by people to justify such concern. When the same or similar incidents happens repeatedly over a certain period of time, and the risk management measures fall short of expectations, the public will feel that the safety of themselves and their families is always under threat, and thus become more vigilant of possible risks. An approach to dealing with hazards is to take a "cautious" attitude towards any negative status perceived by the individuals themselves or society. Any traces relevant to the hazards are likely to touch the sensitive nerve of people. Naturally, they will justify their concern by "attaching and spreading the stigma".

\section{(2) Characteristics of stigmatization}

The first is destructiveness. Stigmatization will distort people's normal risk perception structure, and cause devastating damage to the image of objects, people or systems concerned. In severe cases, the general criteria for justice and safety will be irrationally subverted as what most people care about is simply how abnormal the incidents and how shameful the consequences are. At this time, the public will spontaneously condemn the ability of those responsible for managing and dealing with risks, and even shake the basis of legitimacy of risk management, resulting in chaos in social, economic and political spheres.

The second is rapid contamination. The objects being stigmatized are endowed with unpleasant features that set them apart from other objects. In extreme cases, the objects will be considered a "synonym" for "terrible" and "dangerous". The characteristic of rapid contamination gives them a widespread and shameful influence, and their stigma, based on particular risk perception, can spread quickly before many dangerous outcomes are testified. Moreover, with modern communication networks, the tag of "dangerous" will quickly spread to the same or similar things or people, and will even affect the entire industry, sector and region.

Third, it is not easy to eradicate stigma. Stigma can be easily distinguished, and this can eventually evolve into cultural prejudice that can barely be eliminated over a short period of time. In other words, stigma formed in society is liable to turn into structuralized "cultural fixedness"; if giving attention to stigmatized objects becomes part of everyday life, then no area of life can escape its influence. Eventually, it would be quite difficult for relevant systems, even if they mobilize a mass of social, economic and political resources, to remove stigma.

\subsubsection{The Formation Mechanism of Stigmatization}

\section{(1) Process of stigmatization}

In the process of stigmatization there are five interrelated components: labeling, stereotyping, separation, status loss, and discrimination. ${ }^{3}$ With regard to the stigmatization of risk events, the co-occurrence of these components is also subject to the

\footnotetext{
${ }^{3}$ Bruce G. Link \& Jo C. Phelan. Conceptualizing Stigma. Annual Review of Sociology, 2001 (27).
} 
influence of social culture. The construction process generally includes the following four steps.

First, risk exposure and a "heuristic" approach to risk perception. When a disaster occurs, individuals or groups sensitive to risks will "mark" the objects they think will bring danger. After the exposure of the milk powder scandal, the source of the risk was attached a striking warning label, and the "toxic milk powder" and any factors associated with it drew public attention. A large number of risk signals were soon perceived by more people with media coverage. In everyday life, people have developed a "simplified mechanism" to deal with health risks. Once they receive certain risk-related information, their "common sense and intuition" begin to process information about health risks and help them to make inferences. This information processing process is called "intuitive heuristics". A "heuristic" is quite effective in dealing with hazards spontaneously. It connects intuitive judgment with the probabilistic mechanism by which people handle risk-related information in social contexts: if the probability of losses is high, people tend to avoid risks, and if the probability of gains is high, people are inclined to take risks. ${ }^{4}$ When people are really in danger, the "heuristic" of risk perception can lead to some obvious errors that aggravate the stigmatization of certain objects: first, events that quickly come to mind are believed to be more likely to occur than those that are more difficult to remember, so information about unsafe food is more likely to cause panic; second, a risk's probability of occurrence can vary with the importance of available information or perceived information. The more reports the media make on toxic food and the more access people have to these reports, the more likely most people think the health risks are to occur. Third, the unique events that individuals experience in particular circumstances will be magnified and spread as typical events. Finally, if some information constitutes a challenge to the existing risk judgement, such information will either be ignored or rejected. For example, no matter how the authorities publicized that traces of melamine in milk powder were unavoidable and harmless, the public still believed that such propaganda was unreliable and refused to buy domestic dairy products.

Second, risk identification and interpretation. In the process of stigmatization, the seriousness and higher order impacts of an unfortunate event is determined, in part, by what that event signals or portends. ${ }^{5}$

As shown in Table 3.1, symbolic interpretation of certain risk-related information is more intended to illustrate the emergence of a new type of risk or a greater risk than previous ones. A variety of factors influence people's interpretation, of which a critical one is the public's familiarity with the risk situation, that is, risk identifiability. If an event that is harmful to health or even life-threatening is familiar to the public, such as a traffic accident and even smoking, then it will only attract very limited attention (probably just from the victims' families). If the event is unfamiliar to the public, it will have much greater impacts. For example, the melamine-tainted

\footnotetext{
${ }^{4}$ Daniel Kahneman \& Amos Tversky. Prospect Theory: An Analysis of Decision under Risk. Econometrica, 1979 (47), pp. 263-292.

${ }^{5}$ Paul Slovic. Perception of Risk. Science, 1987 (236), pp. 280-285.
} 
Table 3.1 Signal values in the milk powder scandal

\begin{tabular}{l|l}
\hline Incident (official or enterprises' statement) & $\begin{array}{l}\text { Signal value (symbolic interpretation } \\
\text { by the public or media) }\end{array}$ \\
\hline $\begin{array}{l}\text { Use of melamine to make up for inadequate } \\
\text { protein }\end{array}$ & $\begin{array}{l}\text { A new food safety hazard, posing a greater } \\
\text { threat }\end{array}$ \\
\hline $\begin{array}{l}\text { Officials were held accountable or resigned for } \\
\text { reasons of conscience }\end{array}$ & $\begin{array}{l}\text { The authorities were covering up risks, and } \\
\text { not trustworthy }\end{array}$ \\
\hline Expert debates over pathogenic factors & $\begin{array}{l}\text { The experts had a reputation unwarranted by } \\
\text { any real learning }\end{array}$ \\
\hline $\begin{array}{l}\text { The authorities claimed that only young } \\
\text { children were most affected, and risks could be } \\
\text { reduced by timely treatment or drinking more } \\
\text { water }\end{array}$ & $\begin{array}{l}\text { The authorities didn't care about the affected } \\
\text { children, and knew nothing about the } \\
\text { long-term effects of chemicals on the human } \\
\text { body }\end{array}$ \\
\hline
\end{tabular}

milk powder incident gave rise to much imagination of the complexity of the food industry. Unfamiliar terms such as protein content testing and melamine were considered difficult to understand and control. This, coupled with public technical debate over risk management and some ineffective propaganda, increased public confusion and mistrust about the risk assessment system. Social information identification and over-interpretation of a food safety incident can initiate a process in which the importance of that incident is examined. As long as the incident is considered a portent of something bad, those interpretations will produce a higher order social consequence-stigma. With the publication of "unsafe food" lists by groups or individuals closely concerned with society, the stigma becomes a risk label that can be used by other groups, and direct subsequent risk response behaviors.

Third, separation and status loss. If stigmatized objects are separated as "dangers" by the cultural system, then these factors will be regarded as "alien", and no longer be a due component of "our" society. Such cultural separation, in emergencies, can lead to evasion on a social and even global scale, such as eliminating risk factors, keeping away from hazards, isolating hazards, and withdrawing from unsafe organizations and regions. This is precisely how an incident involves in practice. The public's aversion to one milk powder brand will spread to other brands, and the rejection of milk powder can evolve into doubts about all dairy products, refunding, compensation claims, and even judicial proceedings. This proves that the deepest fears and social actions arise when a good situation suddenly turns dangerous. ${ }^{6}$ In the milk powder scandal, worries and doubts about the safety of milk powder spurred fundamental changes in people's attitudes towards the domestic dairy industry, and the bankruptcy and the decline of business performance of large companies represented a loss of credibility of the dairy industry as a whole. With the deepening of stigmatization, the stigma of milk powder gradually turned to protests against and demands for overhauls of institutional arrangements such as food quality supervision and

${ }^{6}$ Robin Gregory, James Flynn \& Paul Slovic. Technological Stigma. American Scientist, 1995, 83 (3), 220. 
quarantine. When the tension was at its peak, public opinion was directed at functional departments such as the General Administration of Quality Supervision, Inspection and Quarantine, Ministry of Health, and China Food and Drug Administration, as well as their deficient rules and regulations. People no longer trusted the national food safety supervision system, and got disappointed at the system. In the process of risk-related information being interpreted, people not only had an aversion to milk powder on the shelves of supermarkets, but also criticized and derogated milk powder producers, raw material suppliers (dairy farmers), intermediaries, logistics enterprises, and all other businesses related to the production, circulation and sale of milk powder. As a result, the objects being stigmatized would lose many opportunities and see a slump in their social positions. For example, well-known brands might lose their market value, enterprises might be at risk of delisting or even withdrawing from market competition permanently, public figures might lose their social reputation or even face imprisonment, and government bodies might lose the basis of legitimacy and authoritative position. All these reflect the serious consequences of intense stigmatization.

Fourth, cultural fixedness and determination of order. Concentrated derogation and rejection of the stigmatized objects by individuals and groups will mitigate over time, but this does not mean that people forget the hazards; instead, they "archive" the labels of "alien" and "dangerous" in their cultural memory, so that they can make safer responses quickly in the same or similar situations. This stage is the ultimate result of stigmatization. In this sense, stigmatization is in fact a process of culturally positioning risk in order in society. When a stigmatized object is strictly defined as an "anomaly", the profile that it does not belong to the existing system is established. With the process of stigmatization, new risks are named and identified, and enter the classified cultural archives at faster paces, thus reducing intellectual confusion.

\section{(2) Gradients of stigmatization}

Social harm caused by stigmatization is deepened with the risk experiences and risk assessment of the whole society. It has a gradient structure, which is closely related to the perceived level of risk in a particular environment.

First, stigma of things. As risk events generally result from physical changes, what people are primarily concerned about are the things causing widespread anxiety. For example, the focuses of concern are tricky viruses or the hosts of viruses (animals and plants) in public health incidents, poisonous and harmful food, and floods and earthquakes in natural disasters. These physical hazards are the source of crises. Now that they bring risks and threats, it is only natural that people identify and mark them. Especially in the field of health, once food products are alleged to contain substances that pose a threat to human health, people will dispraise all aspects of the industry chain including processing, production, transportation, and sale, and avert them in behavior. Attaching stigma is the beginning of the entire whole process of stigmatization, and has a self-evident purpose, that is, to arouse special attention to the incidents from other groups.

Second, stigma of people and systems. In risk society, materialized risks are always associated with human activities. Any individual or group directly related to 
an event, such as vested interests (producers, local governments) and spokespersons that communicate with the public on behalf of the government, may find themselves stigmatized. The public generally believes that many of the risks in society come from industrial organizations possessing high and new technologies. Therefore, the public's attitudes towards these practical or potential risk makers will become more negative as the image of their products gets worse; this is even true of technical experts that have the power to interpret risks. For experts who have a government background and lack independent research, their authority to interpret risks will be questioned by the public and the media, and their interpretations can even be attacked for being a pretext to help certain systems and organizations shirk responsibilities.

Third, stigma of systems. Generally, people's sense of security and trust are guaranteed by the institutional settings they are familiar with in everyday life. The political and expert systems on which people rely are the important sources of sense of security. ${ }^{7}$ When technical experts and government systems are widely doubted, these systems can barely steer clear. The stigma of systems is reflected in social chaos and large-scale social panic as a result of widespread doubts about whether the government's risk decision-making process is just and effective, and the lack of confidence in whether the new institutional arrangements can bring security expectations. Some improper actions of the government, the main actor of risk aversion systems, will to varying degrees tarnish the image of systems, which will spark more public doubts and worries through risk amplification, eventually leading to the loss of public trust in social systems.

\subsubsection{Health Anxiety and Risk Communication Barriers}

\subsubsection{Health Anxiety as a Way of Life}

Frequent food safety incidents have caused great panic among the public, so "safety comes before regret" become a fundamental principle in daily life. The living environment of modern people is portraited as perilous, and even life itself becomes a problem. It seems that people are facing new risks every day, from toxic milk powder to counterfeit medicine. Once the concern about risk becomes part of everyday life, no area of life can escape it influence. The weakening of ability to take control of one's life has increased the sense of insecurity. "Being at risk" is described as a way of life and is widely accepted by people. The weakening of control even proclaims the most basic human activity to be a risk. Such cultural settings undoubtedly heighten doubts about strange people and things, and fears about events that seemingly threaten people's safety. In a culture where nothing is taken for granted, the inherent sense of insecurity will automatically turn into awareness of risk, and doubts about the problem-solving ability of society makes it more vulnerable. The

\footnotetext{
${ }^{7}$ Anthony Giddens. Modernity and Self-Identity: Self and Society in the Late Modern Age (Zhao Xudong \& Fang Wen, trans.). Sanlian Press, 1998.
} 
intertwining of these worries, anxieties, doubts and vulnerabilities gives people every reason to be cautious. The formation of risk culture as a cautious way of life is exactly a result of introspection and reflection on risk society. ${ }^{8}$ With the advent of global risk society, everyone living in risk society feels the realistic or potential threats. Previous experiences are not enough to justify current behavior, and the risk attributes of modern society have changed the operation logic of society at institutional and cultural levels. When risk becomes a buzzword and penetrates into daily life, it will turn into social consciousness and a cultural atmosphere characterized by insecurity about real life.

\subsubsection{Risk Communication Barriers}

The spread of panic in society will seriously weaken the countermeasures adopted by risk management departments and responsible organizations and in particular, make it difficult to achieve the goal of risk communication fast. As can be seen in the case studies, the obstacles to risk communication are mainly manifested in two aspects.

The first is the discrepancies between risk-related debates. Once an emergency occurs, tricky issues such as the definition of risk, safety range, countermeasures, and responsibility for risk dissemination will become the focus of social debates. It is never easy for different actors (groups/systems) to reach an agreement on these controversial issues. If standardized approaches such as evidence authentication are used for validation, illustration and persuasion strategies, the uncertainty and urgency of the risk event itself often makes it difficult to deduce and make well-informed decisions. More often than not, there are other evidence or optional methods to validate evidence and evade risks, and choosing one strategy always means forsaking the others; as a result, the final consequences will vary wildly in risk assessment. It may take much longer than ordinary people can wait to reject a strategic option or even falsify a risk claim, and the damage spread of physical hazards and public demands for social security will not allow for long discussions.

Risk communication agencies often complain that laypeople cannot deal with risks rationally and the media just "spread hearsay", unable to accurately perceive and judge the risks. In contrast, the general public and the media are often skeptical about the effectiveness of the risk management process of the government and expert systems, arguing that government officials, large enterprises and experts do not always have a thorough understanding of the safety issues people are concerned about and are reluctant to address them heads on. These two tit-for-tat viewpoints indicate that each side's perception and understanding of risk is complex, confusing, sporadic or even incomplete, which often leads to intensified conflicts between the two sides and a sense of distrust in risk communication. Therefore, how to reconcile the perceptual differences among technical bureaucrats, expert systems and the general public is a primary obstacle to overcome for the purpose of smooth risk communication.

\footnotetext{
${ }^{8}$ Scott Lash. Risk Culture (Wang Wulong, trans.). Marxism \& Reality, 2002 (4).
} 
The second is the communication predicament caused by the complexity of risk systems. The term "risk" implies the probability of some hazards in reality, of which harmful and undesirable consequences may occur as a result of natural or human activities. The definition of probability denotes complexity and uncertain causality. Such causality will neither become immediately apparent nor be grasped arbitrarily and in most cases, is difficult to explain and estimate. Risk systems, like other complex systems in the world, are inherently unpredictable, which makes it less likely to make accurate predictions. The fast changes of risk systems go far beyond what mankind can manage. More worryingly, after risk and its consequences exert an impact on society, it will also be subject to the influence of social and cultural structure. These human activities increase the uncertainty of risk, and human interventions are more complicated than physical changes. The ineffectiveness of institutionalized governance measures often brings many consequences that exceed what can be expected in risk management and decision-making.

At this time, people will often hear different views from the government, the media and technical experts: one view is that in face of risks and crises, any explanation is in fact a sign of shirking responsibility, and the government and enterprises must take their due responsibility for disasters; the other view maintains that risk, in some cases, is a "by-product" in the course of human civilization, and an inevitable outcome of social progress, and it is no surprise that some risks are even acceptable. To play a role, the public tend to respond conservatively and ease their sense of insecurity by amplifying risk-related information, thinking that security is much better than regret, and believing what they want to believe. In addition, risk can spark extensive debates at all levels (between people, on the Internet, on television, etc.). When no agreement can be reached quickly in the debates and the spread of risk cannot be curbed, the public will feel frustrated and indignant due to the lack of sense of security. Such indignation can turn any risk issue into a public opinion and moral issue. People may question the motivation of risk communication of the government, enterprises and even the media, lose patience to continue to cooperate with risk management organizations, no longer have trust in them, and condemn the behaviors of risk makers. This will result in more serious social risk consequences, and even affect the legitimation of the regime. Because of such changes, risk communication actions usually lag behind the complicated and variable risk experiences of people, and those responsible for risk management find it difficult to control the pace of risk governance and risk communication, resulting in misunderstanding among the public.

\subsubsection{Factors Influencing Effective Communication}

The first is the public's misunderstanding and limitations of understanding. It is extremely risky in itself to persuade and educate the public to understand risks and judge risks rationally, and even to use their discretion and respond to risks properly. The risk perception of ordinary people is often inaccurate. Generally, when perceiving and judging current events, the public mainly relies on information that is easy 
to extract from memory. In this process, they are liable to be disturbed by some recent information. For example, the frequent occurrence of food safety incidents will conjure up memories concerning food safety, especially those dreadful and painful memories, which will be artificially amplified and thus affect people's risk judgment.

Social interpretations of risk-related information can also arouse new fears. Most people in society are not directly involved in local incidents, but obtain relevant information indirectly. It is a regret that some organizations and individuals, as information intermediaries, fail to accurately assess the types of risks and possible consequences, and their risk interpretations do not always follow the fact-based professional ethics, but are full of exaggerated, dramatically processed and alarming predictions. Consequently, public anxieties will spread to other areas, and disappointment shrouding the society will be played up infinitely. Strong and biased impressions are hard to change. In face of sudden disasters, people will feel somewhat threatened amid fears, worries, horrors or other emotions, resulting in cognitive bias. People's attention span will be disturbed, causing errors in identifying different types of risks. Bad impressions will persist once they are formed, and are inclined to be used to construct subsequent explanations. Irrelevant, preconceived stereotypes may become the basis of cognition and judgment at the next step. As a result, when risk communication agencies present new evidence to help clarify the facts, the "stubborn" public will filter the new evidence: evidence consistent with their inherent beliefs is accepted, while that not is rejected as sophistries and pretexts. In addition, for any risk issue involving sophisticated technology or professional knowledge, the general public, due to the lack of professional knowledge, may overreact or demonstrate other irrational attitudes and behaviors. Knowledge information gap may also hinder the public's chances of understanding risk.

The second is the vulnerability of risk assessment. The premise of modern risk communication is sound risk assessment, which provides factual basis and technical support for communication. Nonetheless, risk assessment is so complex a system that many research systems and researchers, with strong financial support from the government, cannot fully grasp it. There are still divergences in risk terminology and technical definitions between different disciplines. Moreover, it is unlikely to overcome the limitations of existing technologies in a short period of time, or integrate the divided opinions of experts in different research paradigms. This inevitably leads to communication barriers on conflicting issues such as risk definition, risk dissemination, and risk prevention. As enterprises, technical experts, academics and the government view risks in different ways, it is often seen in TV programs, expert interviews and newspaper columns and on online forums that technical experts "of different schools", celebrities and officials pass the buck and attack each other's credibility, data and authority, making the nascent area of risk assessment more vulnerable. As a result, what the public sees is not well-grounded and eloquent warnings, but the dissemination of inconsistent information over which the government and experts are divided. Predictably, without the provision of proper information, there would be no effective risk communication. 
The third factor is the inequality in actual status of the audience and their limited engagement. Ideally, communication should be conducted on the premise that all sides face no pressure and are equal. In risk situations, however, the ongoing state of urgency usually puts the senders of information at an advantage over the recipients. This is because, on the one hand, the government and experts have greater access to first-hand information than the public and the media, and are also more technologically adept at risk assessment; on the other hand, backed by public authority, the government and expert systems are superior to the general public in terms of the status and participation opportunities in communication actions. With a superior status, the administrators are inclined to ignore the actual requests of other participants and become "bureaucratic". In the above-mentioned cases, the senders of information not only failed to accurately judge the degree of attention the recipients were paying to the risks, but also couldn't identify which aspects of the risks were more important to the recipients. As a result, the public receiving information kept asking for information, while the government agencies, without a real understanding of the feelings and needs of the public, were always giving irrelevant answers.

Consultative risk communication emphasizes the status of all sides, but neglects the engagement of the audience. This makes the idea of keeping the public informed and engaging the public in decision-making an empty talk. None of government departments, enterprises or media organizations truly regard the public as a partner, reducing the effectiveness of communication. Even if the public are granted limited opportunities on some occasions, there is another tricky issue: how to determine the individuals or groups that are stakeholders and must be engaged in the discussions. While the issues can be discussed, the urgency of risks and crises leaves little, if any, room for consultation among all participants. Given the time limit for making every risk governance decision, there is little chance for more consultation and greater public engagement in decision-making. No matter how hard it is to overcome the difficulties, necessary and sufficient public engagement will help to ensure the public's right to know, and to build public trust in the government.

\subsubsection{Prerequisites for Risk Amplification}

At least one key element is needed in each round of risk amplification to initiate and sustain the continuous process of risk. Only when an isolated event becomes a public concern and causes social consequences can the process be called social amplification of risk. To launch the process and make it last for a period of time requires multiple factors, such as the concerned public, the active media, stakeholders, institutional engagement of the government, and worrying, new and constantly evolving natural and manmade hazards. 


\subsubsection{Attention from Individuals: A Sufficient Condition of Risk Amplification}

The social construction of risk derives from risk-related experiences of individuals. Any event, if without wide attention from individuals, is unlikely to enter the social context for sense reconstruction. Every individual in modern society is a potential or practical "risk amplifier". In daily life, individuals experience risks in two ways: one is direct experience, which is considered "intuitive", "natural", and "instinctive", while and the other is considered "analytical", "conscious" and "rational". In fact, emotional process is intertwined with rational analysis in all normal minds. ${ }^{9}$ Individuals deal with danger signals in the surrounding environment with feelings and values. In general, individuals' perception of certain risks is considered a deliberate or even rational analytical approach to information processing, but when navigating in a complicated, uncertain, and sometimes dangerous world, relying on emotions is undoubtedly a quicker, simpler and more efficient way. ${ }^{10}$ In the social context of risk, rational analysis is highly dependent on intuitive thinking and is guided by the emotional process. When a valuable signal is sent, individuals will make a preliminary judgment of the event to assess the attributes of risk such as controllability, destructiveness, lethality, and impartiality. Once an event is regarded unknown, dreadful, and unfair by every individual, it is likely to draw close attention and spread quickly through the most direct personal networks.

\subsubsection{Media Coverage: Intermediary in Risk Amplification}

In risk events, traditional print media including newspapers and modern electronic interactive media such as television, the internet and mobile phones are all active in monitoring the real world. The media gather any valuable social issues at any time, especially disastrous events, and then choose some attributes of these events, interpret them according to their news worthiness, and publish the reprocessed information through modern channels, which are an important source for the public to obtain risk-related information. Admittedly, the presentation of risk issues depends on the media, and mass communication increases the "social visibility" of risk situations. As the uncertainty of risk intensifies the demand for information of people from all walks of life, coverage over any risk event by the mainstream media will bring about a rapid "risk amplification effect", directly affecting people's perception of risk. The media is always inclined to hype up or downplay particular risks, and take an active role in affecting the public's risk perception. Dissemination of incomplete information or concealment of facts by the media, coupled with ineffective communication channels, will lead to doubts, worries and fears among the audience. Overreporting

\footnotetext{
${ }^{9}$ Antonio R. Damasio. Descartes' Error: Emotion, Reason, and the Human Brain. New York: Avon, 1994.

${ }^{10}$ Paul Slovic. The Perception of Risk (Feng Xin, Lin Tuyao, trans.) Beijing Publishing House, 2007, p. 14.
} 
over certain phenomena, even misleading situations, can make the public feel that danger is everywhere. The degree of media attention and the amount of information released by the media is undoubtedly a strong signal for people's risk perception. Moreover, intensive media coverage will stimulate social mobilization. In certain cases, continuous, large-scale media coverage will undoubtedly cause public concern and pronounced risk amplification.

\subsubsection{Institutional Participation: An Essential Attribute of Risk Amplification}

The coordination and orderly management of modern society is highly dependent on all kinds of social systems, which are supposed to operate in a timely and effective way to ensure people's safety. When people's "ontological security" is threatened by risks, the systems will get engaged in various ways and with various attitudes, and actively or passively intervene in the process of risk amplification. Firstly, under institutional arrangements, some members of the organizations will participate in risk activities, in which government officials play a major role. It goes without saying that the officials not only take necessary steps in their personal capacity, but more importantly, interpret risks in accordance with their responsibilities and authority. At this time, institutional participation is mainly represented by government spokespersons and senior officials, who demonstrate the risk stance of systems with their words and deeds. In emergencies, however, there will be conflicts between the personal beliefs of government officials and the institutional rules, resulting in "misunderstandings" between the government and the public, the distortion of information and dissemination of information in larger fields. Second, the systems, backed by national power, will initiate social mobilization to cope with sudden risks. This approach itself is intended to spread risk signals, so that all people can feel the urgency of risks and be motivated to unite and cooperate. The top-down issuance and execution of administrative instructions can quickly dispatch human, material and financial resources, enabling the public to take action relying on government-led forces. Third, institutional risk participation also involves the mechanism of rewards (promotion, pay raises and honors) and punishments (demotion, pay cuts, and even judicial disposal) for responsible persons in order to safeguard the seriousness and fairness of the systems and ensure their legitimacy for risk control. Fourth, the systems will adapt to the social consequences of risk amplification and improve and update themselves accordingly, so as to guide, organize and coordinate risk management activities more effectively.

\subsubsection{Effectiveness of Emergency Management and Trust: Inhibitors of Risk Amplification}

In order for a risk amplification process to last for some time, there are another two important factors: the effectiveness of management and the degree of trust. Timely and effective management measures, especially the effect of emergency response and 
the handling of the aftermath, will inhibit the amplification of risk. There are two types of inhibition. One is temporary inhibition. At the micro level, competent authorities mostly respond to emergencies passively and in haste; they neither do a good job in early warning before the occurrence of events, nor reasonably allocate resources or conduct effective risk communication in the evolution process of events. Instead, they deal with problems only when they occur, hoping that the risks can be suppressed and subside as soon as possible. The other is proactive and sound risk management with contingency plans. Risk decision makers and management should constantly absorb the latest results of foreign crisis and risk research, draw on the advanced and successful risk management experiences of foreign countries, conscientiously sum up the domestic experiences and lessons in dealing with major emergencies, timely correct errors in system design, and improve management methods. In this way, they can to the greatest extent keep the situation stable, calm public anger, and motivate the public to coordinate with the government's emergency measures, thus achieving good governance effects.

The effectiveness of risk management, in the final analysis, is based on social trust. The interaction between risk perception and trust has a bearing on the effect of risk management. Pre-existing trust and the credibility of risk management measures allow risk management agencies to "extract" the trust reserve accumulated in the past to deal with sudden events. The premise is that the administrators and risk management agencies have accumulated a lot of "trust" earlier. In a period of profound social transformation, ever-changing interest patterns and more serious "social imbalance and fracture", social relations of various types become unstable and public trust is weakened. Our study shows that emergencies that witnessed the greatest extent of risk amplification mainly occur in social environments with no or little public trust. When there is a climate of distrust among the public, businesses, governments and experts, risk communication efforts will seldom work well. In China, the foundation of public trust in the central government is still solid. This, on the one hand, can be attributed to the long-standing trust reserve of the Party and the government, and on the one hand, is underpinned by the policies and actions benefiting the people. Therefore, whenever the local governments and enterprises are unable to control the consequences of any major emergencies, the central government and its agencies will step in through administrative and other approaches, and formulate plans and take measures based on a broad mass base and public trust, which, to a large extent, will reduce the scope of risk amplification and the depth of influence.

\subsection{Policy Suggestions: Communication Is Key}

In new social risk contexts, now that risks are inevitable, to reduce the influence of risks on social life becomes a primary objective of risk management. If the public's fears of hazards are mitigated through the risk communication efforts of relevant agencies, then the behaviors of stigmatization will decrease substantially. In strategic 
choice of response to risk amplification and stigmatization, the role of risk communication should be underscored.

\subsubsection{Definition of Risk Communication}

Risk communication is a process of accurately explaining and conveying the information obtained after risk assessment to the concerned public, organizations and the international community, and getting feedback from them. Risk communication involves three aspects.

(1) Notification. The initiator of risk communication provides important information about the risks to the public and the media, and informs individuals of the existence, severity and other consequences of the risks. Communicators should be able to interpret complex risks in the simplest words possible.

(2) Empowerment. How to define risk, explain risk, control risk and evade risk when danger comes is a tough issue, because it involves the fundamental interests of different groups and individuals. When most people feel that they are in danger, their opinions are not expressed and their interests not valued, there is a good chance that biases and behavioral conflicts will arise. Risk communication should mediate the opinions and interest disputes from different standpoints, shift from regulation to empowerment, and resolve disputes on the basis of mutual understanding and engagement. Passive groups should be allowed and encouraged to voice their own opinions, make demands, and exchange views on a relatively open platform, so as to improve social relations and enhance social engagement and cooperation.

(3) Reconstruction of relations. In the current global risk environment, the occurrence, amplification and control of risks, whether they are natural disasters, accidental disasters, or public health and social accidents, are all new issues facing Chinese society. There are no experiences at the ready to draw on, or once-for-all solutions. Given that risk has disturbed the existing social relations, risk governance needs to start with the reconstruction of social relations, and effective risk communication should be based on mutual trust and respect for long-term relationships. In order to rebuild harmonious social relations, the public, the media, enterprises and the government all need to participate in risk governance, strengthen communication in mutual learning, enhance trust on the basis of mutual understanding, and repair damaged social relations in the process of information exchange. 


\subsubsection{Significance and Functions of Risk Communication}

\subsubsection{Significance}

From the perspective of policy making, risk governance actually includes communication activities the government conducts with the public with an open attitude and the attention to the voice of different interest groups. The purpose is to make rational use of the government's decision-making power, transform the government from an administrator to a coordinator, and establish a long-term communication and coordination mechanism to resolve risk disputes and achieve the maximum social consensus. It can be seen that risk communication and risk governance complement each other. On the one hand, in order to achieve sound risk governance, the government should fully respect the opinions of different groups in society, be inclusive of diverse social actors and public representatives, devise different communication strategies, rationally interpret, understand and have public discourse, and finally arrive at a temporary definition and understanding of controversial risk issues. On the other hand, effective risk communication can cultivate social tolerance for conflict, and provide risk management agencies with the basis and institutional assessment tools for resolving risk debates. In policy making, effective risk communication can not only promote understanding between stakeholders and social groups, but also enable risk assessors and managers to better understand the people's voices and their concerns.

From the perspective of the policy implementation process, risk communication is an action to make "governance policy" clearly known to and understood by the public. As risk communication covers a wide range of social and cultural perceptions and controversial perspectives, it becomes part of the overall risk governance process from the very beginning, and is an important referable step throughout the process from the definition of the risk framework, risk assessment and democratic risk decision-making to risk control, and affects other steps in a circular way. Risk communication is considered to play a core role in circular interactions with risk assessment, disaster identification, policy formulation, policy implementation, and policy assessment. In this sense, risk communication is the "soul" of risk governance, while risk assessment and risk control, among others, are the "flesh and bones".

\subsubsection{Functions}

(1) Protection. In face of danger, individuals or groups will make protective or defensive behaviors. The stronger the danger signals they feel, the more rigorous the protective measures will be. Except those experiencing risks personally, people's protective behaviors mostly come from indirect experiences, of which information disclosure by the government, media reports and interpersonal communication will to a large extent raise the perceived level of risk. Under the pressure of risk, people's ability and effectiveness of dealing with 
external information will also be reduced. Emotional arousal and anxiety caused by a strong sense of threat will prompt the public to instinctively opt for "selfdefense" to avoid risk. It should be pointed out that when risk management agencies and administrators should publish and disseminate to the public any risk-related information in a reasonable and moderate way, and guide the public to take appropriate protective actions to reduce harm.

(2) Education. Risk management agencies should timely publish information on incidents and disasters, inform the public of the types of risks, preventive measures and possible consequences, and have a tolerant attitude towards people's behavior. In doing so, they can educate the public by disseminating necessary knowledge about risk, promoting risk awareness, and clarifying the acceptable risk range. An important goal of risk communication is to tell the public that: first, scientific knowledge and risk assessment can provide guidance for decision-making; second, the decisions, no matter how logical they are, cannot give the ultimate answers to all risk issues, which are not just technical issues about avoiding risk, but also intertwined with political, social and cultural factors. Therefore, in risk communication, it is necessary to lower the public's unrealistic expectations of informed decision-making, thereby reducing the public and the media's misunderstanding of government agencies, and increasing mutual understanding and trust.

(3) Mediation. Modern risk communication emphasizes interaction and public participation, and sees multilateral engagement in policy making as a major advance in democracy. Risk communication differs from risk dissemination in that it pays attention to the feedback and feelings of the audience, and no longer regards the public as a passive recipient of information. Instead, it gives the public the opportunity to express their own views, and mediates conflicts of interest through proper empowerment. Taking risk communication as one of the tools for the government to balance various interests also highlights the coordination function of risk communication in the process of public policy implementation. Since risk issues are unavoidable in modern society, it is paramount to strike a balance between policymakers and the public by means of risk communication. The government, enterprises and other organizations should not ignore relevant risks, and the public need not overreact to any risks. When risk governance decisions normalize and institutionalize risk communication, the society has found the way to define the acceptable risk range and better reduce risks, thus capable of coordinating the conflict between those who create risks and who bear risks.

Fourth, trust and confidence booster. In emergencies, people always wish to get support and backup. Effective risk communication first can demonstrate an open attitude of risk management agencies to the public and the media, and make a good impression on the audience. Then, after a series of actions such as the implementation of crisis management measures, the release of risk-related information, and the response to queries from the media and opinion leaders, the public's tension, anxiety and panic will be greatly alleviated, and they will restore confidence in overcoming difficulties, and become more dependent government's risk management 
system. Once people have confidence in institutionalized risk governance mechanisms, public trust that has been dented in emergencies will be restored to a certain extent.

\subsubsection{Channels of Effective Communication}

\subsubsection{Communicator and the Audience}

The government is the communicator in risk communication. Once an emergency occurs, the government, which possesses an abundance of public resources and public power, will automatically become the vanguard of social order and public security, and one of its primary responsibilities is to do a good job in risk assessment, information disclosure, and interpretation. The risk attributes of major emergencies and serious consequences such as risk amplification brought about by improper communication determine that the government must take the initiative to play a leading role in risk communication. The government should release information to targeted groups or the public as a whole in a planned way, select suitable channels of information release, oversee the effects of information release, and explain the information released, so as to educate the public and guide and reconstruct the public's risk perception and action.

Before conducting risk communication, risk governance decision-making bodies should get prepared, including identifying potential difficulties and stakeholders. These stakeholders include not only individuals, groups and organizations directly affected by the incidents, but also those who may bear the risks, as well as any other individuals and organizations that have to deal with the risks.

According to the range of ripple effects of risk amplification, there are three types of audiences in risk communication. The first is "primary audience", referring to the main groups of people who are going to be affected by risk-related information, and a great deal of information in risk communication is designed for them. The primary audience includes direct victims of incidents, local residents, and enterprises and other organizations based in the locality. They constitute the group in the most urgent need of safety. Whether their right to know can be ensured through effective risk communication will have influence on the effect of the subsequent risk amplification. The second type is "secondary audience", including those likely to be affected by risks in addition to the "primary audience". The secondary audience consists of the residents, groups and organizations outside of the core threatened areas, and even government agencies and economic organizations outside the territory. Because they are far from the core areas of incidents and cannot directly feel the physical damage of risks, their risk perception is based on imagination and indirect experiences, and they may also play the biggest role in spreading rumors, making them the most unstable part of risk amplifiers. The third type of audience is "medium audience". Though the medium audience is not the main targeted group of risk communication, information needs to be transmitted through them to the first and second types of audience. 
The medium audience includes reporters, online opinion leaders, and so on. They play a decisive role in risk communication and social amplification of risk. They pass on risk-related information and knowledge from top to bottom, and can also construct bottom-to-top risk issues and perform the responsibility for risk education and risk communication.

\subsubsection{Risk Communication Channels}

The paths of social amplification of risk can also be used as communication channels in risk governance. When risk management agencies ignore the effect of social amplification of risk, these channels become a passage for spreading rumors and anxieties; and when the agencies are aware that risk amplification can bring serious and harmful consequences, these channels can be transformed into a pathway to release accurate information, adopt proper suggestions, and take coordinated action.

First, official channels. Information on major domestic incidents at critical moments is issued by the authorities through official channels. The voices and intentions of the government can be transmitted via several channels: first, the press conferences of the State Council (including its ministries and commissions); second, the meeting resolutions of the CPC Central Committee and its Political Bureau are released by the authoritative media including the Xinhua News Agency, People's Daily and CCTV; third, the instructions and on-site guidance of the leaders at central and provincial levels, which allow them to directly interact with the public, listen to the views of the grass-roots, and respond quickly and efficiently.

Second, news dissemination. Risk communication has to make risk issues visualized by presenting them. In this process, the mass media serves as an important bridge between issues and the public, and the intermediary for the public to understand risk issues. People obtain risk-related information mainly via the mass media (television, radio, networks, and newspapers), of which television is regarded as the most important and reliable channel by the general public.

Third, the Internet. The new media represented by the Internet is of growing importance for the dissemination of information. The Internet has become an important node in social amplification of risk, and certainly a key link in risk communication. With an enormous amount of information, the Internet is becoming a main source of public opinion. The netizens can express their views on public affairs and social phenomena through information networks and in multiple ways, such as posting comments on hot news on web portals, discussing on online forums or BBS, writing and reposting blogs, and exchanging information via instant messaging services. Today, risk management agencies have attached growing importance to the role of online public opinion in risk governance, and started to solicit opinions from the public online, and advocate internet-based supervision over public affairs.

Fourth, interpersonal communication. Interpersonal communication in risk communication is different from "hearsay", to say nothing of "rumors". It is an organized action grounded in fact, and a behavior of self-conscious risk learning, risk early warning and risk education of the residents under the guidance of the government, 
in which disaster-related information and mutual aid signals are disseminated and shared mainly through friends and relatives.

Fifth, other channels. When some scientific, agreed conclusions are drawn in risk assessment, risk management agencies can promote correct concepts and knowledge through advertising, public meetings, environmental and health consultations, performances, safety brochures and so on. Risk communication conducted in popular and easy-to-understand ways can often achieve unexpected results.

\subsubsection{Risk Communication Principles}

Timeliness. Risk communication should precede "hearsay" and rumors. The fact that some incidents evolve into public crises and cause unexpected consequences is because authoritative risk communication comes too late and may even be put off deliberately. The principle of timeliness requires that risk-related information should be released as early as possible.

Transparency. To release all "details" that can be made public is a significant test of the managerial ability of risk management agencies. It is the practice of concealing risks on purpose of some primary-level government departments that has resulted in more serious consequences. The disclosure of risk-related information and risk response details is based on the progress in risk assessment and investigations. It is an irresponsible behavior to make public any information without scientific verification and strong evidence in that it will cause greater panic and suspicion in society.

Initiative. Seeing incidents as "bad things", the administrators mostly take the approach of "risk attenuation" to reduce communication with the public and the media, but this is not the best policy. True risk communication should be based on long-term relationships characterized by mutual trust and respect. Risk communication, in essence, is to give official reply to public demands. Modern risk management requires the administrators to take the initiative to assess risks, contact the media to release information, understand the actual needs of people, and mobilize more social resource for joint risk governance efforts.

Moderation. Risk communication is not simply pouring out all the information to the public and the media. In fact, the primary concern of people in face of risks is the severity of hazardous events, and then they pay attention to specific countermeasures and other information. This forms a tiered attention model centered on the levels of risk. Therefore, risk communication should take into consideration the levels of perception of the public, and be conducted in an orderly, appropriate and gradual manner.

Equality. Because there are obvious differences in risk perception and understanding among technocrats, risk experts, the general public and the media, and the existing expert systems always voice their opinions on behalf of their own organizations, the public will feel disadvantaged in terms of status. Though "absolute equality" is impossible in real communication, risk management agencies and experts should keep an open mind, think things from the perspective of the threatened sides, allow public opinion and online public opinion leaders to express their views, and 
encourage participation of the residents at the community level. Such equal participation may better meet public expectations.

\subsubsection{Measures for Effective Communication}

\subsubsection{Enhancing Public Understanding of Risk}

It is necessary to strengthen public understanding of certain risks, and correct incorrect information. The key to this, in addition to increasing risk awareness and holding science outreach activities, lies in mass communication that releases massive, accurate and systematic positive information. Meanwhile, it is also essential to overcome the uncertainty and ambiguity brought by risks, develop necessary risk response practices, and improve personal scientific literacy.

\subsubsection{Improving Media Coverage}

Given the limitations of the media itself and the interests associated with risk issues, the biases and unilateral risk construction of the media are no surprise. For this reason, it is necessary to improve the media's performance in risk communication. For example, the media should improve the ability to understand risks and identify the sources of risks, improve the practitioners' communication skills, constantly sum up lessons from past experiences, and help the public better understand and clarify risk issue. A sound news information cooperation and exchange mechanism should be developed so that the practitioners can get in touch with experts and scholars who are willing to cooperate so as to make reasonable and relatively consistent judgments. News organizations can share information to make their reports more reliable. Moreover, the media should put the interests of the public at the core, listen to the voice of the people, and highlight public interests and reflect the public's safety demands in their reports.

\subsubsection{Rebuilding Public Trust in the Government}

Public trust in institutions holds key to addressing the problems associated with risk perception. It is the basis for properly handling the negative consequences caused by risk perception. Rebuilding government credibility is core to curbing social amplification of risk. Now that many risks derive directly or indirectly from the government, governments at all levels, in face of risks and crises, should release information in a timely and accurate manner, guide public expectations about risks, engage the public 
in risk management, and put in place just institutional arrangements to handle those directly responsible for creating risks. Only in this way can government credibility be rebuilt in a social climate of distrust, and social forces be mobilized to jointly cope with the risks and crises that are ongoing or may occur. 